\title{
2 Autoeficácia em Contexto de Saúde: achados na literatura brasileira
}

\section{Luiza Cristina Mauad Ferreira ${ }^{1}$ Roberta Gurgel Azzi ${ }^{1,2}$}

O maior benefício que um tratamento psicológico pode oferecer não são remédios específicos para problemas particulares, são as ferramentas necessárias para lidar efetivamente com qualquer situação que apareça (BANDURA, 1997, p. 318).

"Um estado de completo bem-estar físico, mental e social e não somente ausência de afeções e enfermidades" é a definição de saúde, adotada pela Organização Mundial de Saúde (Constituição da Organização Mundial da Saúde, 1946, p. 1), que implica ir além de um valor pessoal, passando a ser um direito coletivo fundamental da pessoa humana. Essa definição estabelece ser a saúde um direito de todos independentemente de condições econômicas, religião, raça e situação econômico-financeira, e apresenta uma nova dimensão relacional do sujeito com o mundo em que está inserido, suas relações pessoais, de trabalho e com a comunidade em que vive, $\mathrm{e}$ não simplesmente o bom funcionamento do organismo biológico. Surge, assim, a concepção de saúde social, que considera o bemestar social para garantia da saúde física e mental dos indivíduos.

Essa mudança de concepção de um modelo de doença para um modelo de saúde tem trazido contribuições de diferentes áreas para a compreensão do funcionamento humano, inclusive a área da psicologia. Mudanças de hábitos de vida, como relações familiares, alimentação, condições de moradia, trabalho e lazer, têm gerado desgastes constantes, tanto físicos como emocionais, levando o indivíduo a sofrimentos e, em decorrência, ao adoecimento.

Apoio

${ }^{1}$ FAPESP

\#2015/15211-2

${ }^{2} \mathrm{CNPq}$

\#302668/2016-0
Bandura (1997) afirma que "a qualidade da vida humanaé fortemente influenciada pelos hábitos de vida (p. 1)”. Na abordagem sociocognitiva por ele formulada, a Teoria Social Cognitiva (TSC) (Bandura, 1986), o objetivo da promoção da saúde é exercer controle 
Autoeficácia em Contextos de Saúde, Educação e Política

Roberto Tadeu laochite \& Roberta Gurgel Azzi

Organizadores

para continuar lendo, clique aqui 